Background The role of gold salts in the present therapy of rheumatoid arthritis (RA) remains controversial.

Objectives To analyse the clinical efficacy (according to ACR response criteria) of a therapeutic protocol, that includes sodium aurothiomalate as first option DMARD in patients with recent onset RA.

Methods All patients with RA (ACR diagnostic criteria) for less than two years disease duration and no previous DMARD therapy, attending our Rheumatology Units during 1998-99, have been included in a therapeutic protocol, in which the first administered DMARD was sodium aurothiomalate at a dose of $50 \mathrm{mg} /$ week. According to the ACR response at 6 months (no improvement, ACR-20 or ACR-50) patients were treated with methotrexate (MTX) alone, aurothiomalate plus MTX or aurothiomalate alone, respectively. Low dose of steroids $(<10 \mathrm{mg} / \mathrm{d}$ of prednisone) were allowed and intraarticular therapy with triamcionolone hexacetonide was performed in large joint with persistent synovitis.

Results Forty seven $(7 \mathrm{M} / 40 \mathrm{~F})$ patients were included (age:54 \pm 16 years; disease duration: $10 \pm 7$ months; $\mathrm{RF}+: 40(85 \%))$. The percentages of ACR responders at 6 and 12 months were as shown at the Table 1 . Twenty-four per cent of patients discontinued gold salts due to adverse events or inefficacy at 12 months. Aurothiomalate was continued in $61 \%$ of patients as monotherapy and in $15 \%$ of patients in combination with MTX.

\begin{tabular}{lllll}
\multicolumn{5}{l}{ Abstract FRI0026 Table 1 } \\
& Remission & ACR-20 & ACR-50 & No improve \\
\hline 6 months & $11 \%$ & $61 \%$ & $50 \%$ & $28 \%$ \\
12 months & $27 \%$ & $52 \%$ & $30 \%$ & $21 \%$ \\
\hline
\end{tabular}

Conclusion Gold salts still have an important role in RA treatment. The use of aurothiomalate should be taken into account in the present therapeutic strategies of patients with early RA.

\section{FRI0027 5-AMINOLEVULINIC ACID INDUCED PROTOPORPHYRIN IX FORMATION IN ARTHRITIC SYNOVIAL TISSUES: AN APPROACH FOR SYNOVIAL PHOTODYNAMIC THERAPY IN ARTHRITIS}

${ }^{1} \mathrm{G}$ Kirdaite, ${ }^{2} \mathrm{~N}$ Lange, ${ }^{1} \mathrm{~N}$ Busso, ${ }^{2} \mathrm{H}$ Van den Bergh, ${ }^{3} \mathrm{P}$ Kucera, ${ }^{1} \mathrm{~A}$ So. ${ }^{1}$ Laboratoire de Rhumatologie, Université de Lausanne; ${ }^{2} D G R ;{ }^{3}$ Institut de Physiologie, Université de Lausanne, Lausanne, Switzerland

\subsection{6/annrheumdis-2001.1156}

\section{Background}

Objectives To determine the optimal conditions for synovial accumulation of protoporphyrin IX (PpIX) and light induced synovial cytotoxicity in arthritis in vitro and in vivo.

Methods In vitro studies: Synovial biopsies from patients with osteoarthritis $(\mathrm{OA}, \mathrm{n}=9)$, rheumatoid arthritis $(\mathrm{RA}, \mathrm{n}=3)$ and synovial tissues from mice with antigen-induced arthritis (AIA, $n$ $=9$ ) were incubated with different concentrations of 5 -aminolevulinic acid hexyl-ester (h-ALA), a protoporphyrin IX (PpIX) precursor. Tissue PpIX content was determined by microspectrofluorometry. Following photoexcitation, the synovial tissues were evaluated by Sytox-Green fluorescence for cell death.

Animal studies: h-ALA was injected intra-articularly into knee joints of mice with AIA $(n=40)$. Following photodynamic therapy (PDT) in vivo, joint inflammation was assessed by technetium scintigraphy and histology.

Results In human biopsies, the highest fluorescence intensity was observed after incubation with $0.5-1 \mathrm{mM}$ h-ALA. Kinetic studies showed that PpIX accumulation in human tissues reached a peak at $3 \mathrm{~h}$ in OA and increased linearly up to $6 \mathrm{~h}$ in RA. Murine tissues showed highest fluorescence intensity at a concentration of $4 \mathrm{mM}$ in vitro and $8 \mathrm{mM}$ in vivo. By fluorescence microscopy, PpIX was localised to the synovial lining layer, endothelial cells and macrophages. Irradiation of pre-incubated tissues in vitro led to significant cell death. PDT in vivo in AIA led to a statistically significant reduction of histological parameters of joint damage in irradiated joints.

Conclusion Our findings suggest that PDT based on PpIX accumulation in the synovial membrane may be a rational basis for photodynamic synovectomy in arthritic diseases.

\section{FRI0028 SUPPRESSION OF EXPERIMENTAL ARTHRITIS BY TREATMENT WITH A NOVEL DMARD, SMP-114}

F Nishikaku, S Tagashira, K Hagi. Research Center, Sumitomo Pharmaceuticals, Osaka, Japan

\subsection{6/annrheumdis-2001.1157}

Background A more promising therapeutic approach to rheumatoid arthritis would be to maintain joint function. Our studies have been performed with the above goal in mind and showed that some azole compounds meet these requirements. SMP-114, a novel isoxazole derivative, was selected from them and characterised as a compound with antiarthritic activity and without any cyclooxgenase inhibitory activity.

Objectives The objective of these studies was to evaluate the effect of SMP-114 on joint oedema, bone resorption and ankylosis in experimental models of rheumatoid arthritis.

Methods Adjuvant arthritis was induced in Lewis rats by a single injection of Mycobacterium butyricum in the plantar surface of right hindpaw on day 0 , and animals were treated therapeutically (days $10-24$ or days $17-21$ ) with SMP-114. Anti-inflammatory activity was determined by measurements of paw swelling. The protective effect on joint integrity was determined by measuring radiographic and histological changes. Collagen-induced arthritis was induced in DBA/1J mice. Animals were immunised intradermally at the base of the tail with type II collagen (day 0 and day 21). SMP-114 was administered orally (days 0-49). Efficacy was assessed clinically, histologically and radiographically. Results Treatment (days 10-24) of adjuvant arthritis with SMP114 significantly reduced paw oedema with a minimum effective dose of $10 \mathrm{mg} / \mathrm{kg}$. This was accompanied by a more extensive reduction in bone and cartilage destruction around the metatarsal-phalangeal joint, as assessed by histologic and radiographic examinations. SMP-114 was also able to significantly ameliorate full-blown adjuvant arthritis. When daily administration of SMp114 began on day 17, well into the chronic destructive phase, the agent produced a dose-response effect on paw oedema, with a minimum effective dose of less than $2.5 \mathrm{mg} / \mathrm{kg}$. The compound (range $2080 \mathrm{mg} / \mathrm{kg}$ ) demonstrated a capacity for ameliorating joint inflammation (paw oedema) and protecting joint structure coincident with a decrease in the number of osteoclasts in articular lesions in mice with collagen-induced arthritis. SMP-114 also showed anti-fibroblastic effect and, as a result, reduced a frequency of development of ankylosis in these models. This profile 
of activity was not shared by nonsteroidal anti-inflammatory drugs such as indomethacin.

Conclusion Our studies show that SMP-114 has remarkable protective effects on the joint of adjuvant arthritic rats and collageninduced arthritic mice. These data suggest that SMP-114 will show greater benefit in slowing joint destruction and disease progression in rheumatoid arthritis in humans.

\section{FRI0029 TREATMENT OF THERAPY-RESISTANT RHEUMATOID ARTHRITIS (RA) WITH IMMUNOADSORPTION}

${ }^{1} \mathrm{H}$ Haschkovitz, ${ }^{1} \mathrm{O}$ Warchol, ${ }^{1} \mathrm{~A}$ Dunky, ${ }^{2} \mathrm{G}$ Leitner, ${ }^{2} \mathrm{~N}$ Worel, ${ }^{2} \mathrm{P}$ Höcker. ${ }^{1}$ Department of Rheumatology, Wilhelminenspital; ${ }^{2}$ Department of Transfusion Medicine, University Hospital, Vienna, Austria

\subsection{6/annrheumdis-2001.1158}

Background Refractory RA - periods of untreatable progression. Objectives Failure to conventional therapy with DMARD`s including immunosuppressive drugs can be a major problem in patients with refractory RA. We studied especially the clinical efficacy of an additional treatment with immunoadsorption using a protein A column. Totally six patients with rheumatoid factor positive RA according to the criteria of ARA (female, mean age: 45 years (20-65), duration of disease: 4-12 years) were observed in a follow-up of 6 months.

Methods Plasma was separated by a continuous flow cell separator (A S 104, Fresenius) with venous access. Separated plasma passed down columns containing protein A sepharose (Excorim, Lund, Sweden). The application was performed every second day (number of treatments $=65$ ). Two times of patient`s total plasma volume was treated. Beside clinical parameters like morning stiffness, number of swolen and painful joints and pain scale, values of IgG, IgM and IgA, peripheral blood counts, total protein and coagulation parameters were evaluated before and after each procedure.

Results Four patients showed a significant, sustaining improvement in clinical syndroms over five months.

In two cases there was only minimal and transient success. All six patients tolerated the treatment very well. In three patients transfusion of packed red cells, in two patients also substitution of $20 \%$ human albumin was necessary in addition to IgG support.

Conclusion Protein A Immunoadsorption can be considered as a method, which sometimes improves the course of refractory RA and overcomes periods of untreatable progression.

\section{FRI0030 TREATMENT WITH ETORICOXIB (MK-0663), A COX-2 SELECTIVE INHIBITOR, RESULTED IN MAINTENANCE OF CLINICAL IMPROVEMENT IN RHEUMATOID ARTHRITIS}

${ }^{1} \mathrm{SP}$ Curtis, ${ }^{2} \mathrm{~J}$ Maldonado-Cocco, ${ }^{3} \mathrm{BR}$ Losada, ${ }^{4} \mathrm{AE}$ Gallagher, ${ }^{5} \mathrm{~J} \mathrm{Ng},{ }^{5} \mathrm{~S}$ Mukhopadhyay, ${ }^{1}$ BJ Gertz. ${ }^{1}$ Clinical Research; ${ }^{2}$ Rheumatology, Instituto de Rehabilitacion Psicofisica, Buenos Aires, Argentina; ${ }^{3}$ Prof. Rheumatology, Centro Nacional de Enfermedades Reumaticas, Caracas, Venezuela; ${ }^{4}$ Clinical Research, British Hospital of Buenos Aires, Buenos Aires, Argentina; ${ }^{5}$ Biostatistics, Merck \& Co., Rahway, USA

\subsection{6/annrheumdis-2001.1159}

Background Prostanoid synthesis is catalysed by two distinct cyclooxygenase (COX) isoforms; COX-1 (constitutive) and COX-2 (inducible). NSAIDs such as aspirin, ibuprofen and indomethacin inhibit both COX isoforms. Etoricoxib has been characterised as a COX-2 selective inhibitor with doses up to $150 \mathrm{mg}$ QD (100-fold selective in human whole blood assay).

Objectives Characterise the clinically active dose range and the longer term efficacy of etoricoxib in rheumatoid arthritis (RA).

Methods Double-blind, randomised, placebo-controlled study conducted in 54 centres worldwide in 581 RA patients. Following withdrawal of prestudy NSAIDs and demonstration of a worsening of disease activity, eligible patients were randomised to once daily oral therapy with either placebo $(n=123)$, etoricoxib $10 \mathrm{mg}(\mathrm{n}=78), 60 \mathrm{mg}(\mathrm{n}=126), 90 \mathrm{mg}(\mathrm{n}=134)$, or 120 $\mathrm{mg}(\mathrm{n}=120)$ and assessed after 2, 4 and 8 weeks.

Results Over the initial 8-week period (Part I), patients taking etoricoxib $90 \mathrm{mg}$ and $120 \mathrm{mg}$ demonstrated similar efficacy, with both treatment groups showing significant improvements compared to placebo (average change from baseline $\mathrm{p}<0.05$ ) for the primary endpoints of patient and investigator global assessment of disease activity and key secondary endpoints of patient global assessment of pain and Stanford Health Assessment Questionnaire (HAQ) Disability Index. For the patient assessment of disease activity, there was -9.41 , and $-9.15 \mathrm{~mm}$ (VAS) mean difference vs. placebo (least-squares mean difference vs. placebo, responses averaged over weeks 2 to 8 for the 90 $\mathrm{mg}$, and $120 \mathrm{mg}$ etoricoxib treatment groups, respectively). Data demonstrating that longer term efficacy was maintained (up to 52 weeks) will be presented.

Etoricoxib was generally well-tolerated during Part I. There were no statistically significant trends for patients with one or more adverse events (AEs), serious AEs, drug-related serious AEs, or discontinuations due to AEs ( $\mathrm{p}>0.05$, etoricoxib vs placebo). Safety (up to 52 weeks) was generally consistent with that observed during Part I.

Conclusion Etoricoxib 90-120 mg improved the symptoms of RA over 8 weeks and was well tolerated, with longer term efficacy data demonstrating maintenance of effect. Replicative phase III studies are ongoing to evaluate the efficacy and safety of etoricoxib in patients with RA.

\section{FRI0031 CYCLOSPORIN-A PLUS METHOTREXATE COMBINATION THERAPY IS AS SAFE AS CYCLOSPORIN-A ALONE IN PATIENTS WITH EARLY RHEUMATOID ARTHRITIS}

${ }^{1} \mathrm{AH}$ Gerards, ${ }^{2} \mathrm{RB}$ Landewé, ${ }^{1} \mathrm{AP}$ Prins, ${ }^{3} \mathrm{GA}$ Bruijn, ${ }^{2} \mathrm{HS}$ Goei The, 'BA Dijkmans. ${ }^{1}$ Rheumatology, Vrije Universiteit Medical Centre, Amsterdam; ${ }^{2}$ Rheumatology, University Hospital, Maastricht; ${ }^{3}$ Rheumatology, Medisch Centrum, Leeuwarden, The Netherlands

\subsection{6/annrheumdis-2001.1160}

Background Combination therapy with cyclosporin-A (CsA) and methotrexate (MTX) has shown to be advantageous in early RA. A major concern is still the possibility of synergistically increased toxicity.

Objectives To assess whether long-term combination therapy wit CsA and MTX results in more renal and hepatic toxicity than CsA alone.

Design A randomised double blind placebo controlled trial of 48 weeks duration.

Methods 120 patients with active RA: mean age 52 yrs, mean disease duration 3 months. Patients received CsA and MTX or CsA and placebo. MTX was started at $7.5 \mathrm{mg} / \mathrm{week}$, and was increased to $15 \mathrm{mg} / \mathrm{wk}$ after 16 weeks. CsA was started at 2.5 $\mathrm{mg} / \mathrm{kg} / \mathrm{day}$, and was increased to a maximum of $5 \mathrm{mg} / \mathrm{kg} /$ day. Additionally, all patients used folic acid $1 \mathrm{mg} / \mathrm{d}$. Patients who did not have an ACR 20 response at week 24 were withdrawn. 